\title{
POWER QUALITY ENHANCEMENT BY IMPROVING VOLTAGE STABILITY USING DSTATCOM
}

\author{
Priyanka Rani ${ }^{1}$, Ashish Sharma ${ }^{2}$ \\ ${ }^{l}$ M.Tech Scholars, Electrical Department, Lovely Professional University, Punjab, India \\ ${ }^{2}$ Assistant Professor, Electrical and Electronics Department, Lovely Professional University, Punjab, India
}

\begin{abstract}
Power Quality issues occur in the power system due to the non standard voltage, current and frequency. For the better power quality there are two things two consider that voltage magnitude should be constant and waveform should be undistorted. If the reactive power in the line varies the active power varies. As the active power is proportional to the magnitudes of the voltages at the sending end and receiving ends, the voltage in the line gets affected due to the reactive power variations. Both the former and the later one can be achieved by maintaining the reactive power within the limits. Whenever there is a change in the reactive power correspondingly the active power and hence voltages gets disturbed. As the load gets changed the impedance of the line also changes correspondingly. If the impedance of the line increases after connecting the load, the active power gets reduced. Similarly if the impedance of the line gets decreased after connecting the load the active power increases. Both the conditions violate the stability of the system. So the design of the power system should be in such a way that stability of the system is maintained by overcoming all these violations. This paper presents the mitigation of voltage sag and swells with different types of load by maintaining the reactive power within limits. For achieving the required phenomena DSTATCOM is used. DSTATCOM implemented in this system makes use of VSC and maintains the voltage magnitude within limits under the influence of voltage sags and swells by supplying the reactive power to the line in case of sag and by drawing the reactive power of the line in case of swell.
\end{abstract}

Keywords: DSTATCOM, Voltage Stability, Sag/Swell, Voltage Source Converter.

\section{INTRODUCTION}

Electrical energy is the most convenient form of energy as it can be converted into various forms of energy for different purposes as lighting, heating, cooling and for number of applications. Therefore the consumption of electricity is increasing day by day throughout the world. As the consumption of electricity increases there will be a serious shortage of power. The shortage may be due to the increase in the consumption or due to the malfunctioning of the equipment in the system. The ultimate way to decrease or overcome these shortages is to increase the power generation tremendously or to overcome the situations of malfunctioning. This paper presents a solution to overcome the later situation. To overcome these problems suitable measures are taken before, like circuit breakers, isolators etc, while taking these safety measures there may be conditions of switching on extra equipment or switching off of the present equipment. Due to this phenomenon there may be a reduction of reactive power or increase of reactive power in the system which leads to the active power change. There may be a sudden change in the load which for instant reduces or increases the active power which in turn leads to the voltage change and distorted waveforms. If any short circuit or open circuit in the line or phase occurs, the voltage value changes in the line. All of these issues which are related to problems occurring in the system disturbing the stability are called as power quality problems. If these problems are not eliminated by using a suitable control technique, the entire system may lose its stability. By keeping the necessity of power requirement in day to day life nowadays there is a need to focus on power quality issues to solve the economic challenges with the power system throughout the world. The term power quality describes by the magnitude and waveforms of the voltage and current in power system, for standard power quality means voltage should be within the limit and waveform should not be distorted.

An electric distribution system can be defined as the link between the bulk power source and the utility. The non standard voltage, currents affecting the end user equipments which cause equipment outage and interrupting the optimum power flow through the system. The common problem relating with the voltage profile is sag and swell which ranges from $10 \%$ to $90 \%$ of the nominal voltage level.

\subsection{Power Quality}

The consideration of power quality problems is an important factor to meet the consumer's demands. On the other side ,for the electrical supply industries, the quality of power delivered is one of the distinguishing factor for ensuring customer loyalty in this present competitive and deregulated market .To address the needs of energy consumers trying to improve 
productivity through the reduction of power quality related process stoppages and energy suppliers trying to maximize operating profits while keeping customers satisfied with supply quality, innovative technologies providing the key to cost-effective power quality enhancements solutions. Various power quality solutions are available; the question for a consumer or utility facing a particular power quality problem is which equipment providing the better solution means lesser harmonics [1].

\subsection{An Introduction to Power System Harmonics}

Basically the main objective of the electric utility is to deliver sinusoidal voltage at fairly constant magnitude throughout their system end [2]. Then this objective is complicated by the fact that there are number of non linear loads on the system that producing harmonic currents in the system. These harmonic currents result in distorted voltages and currents that can adversely impact the system performance in different ways. As the number of harmonic producing loads has increasing year by years, it has become increasingly necessary to address their influence when making any additions or changes to an installation. To appreciate the impact of this phenomenon, there are two important concepts we should to keep in mind with regard to power system harmonics. The first is the nature of harmonic-current producing loads (non-linear loads) and the second is the way in which harmonic currents flow and how the resulting harmonic voltages developing at the end of the system [3].

\subsection{Effects of Harmonics}

The basically voltage and current harmonics effects throughout the power system are:

- The possibility to amplify of harmonic levels resulting from series and parallel resonances.

- The reduction in efficiency of the generation, transmission and utilization of electric energy.

- Insulation ageing of electrical plant components with consequent shortening of their useful life.

- In Malfunctioning system or components of the plant.

\section{DSTATCOM}

It is a FACTS device which is installed for the support of electricity networks which have poor power factor and voltage regulation also, commonly it is use for the stabilization of voltage and to improve power factor of that network. It is a voltage source converter based device, which can work as reactive power source or as a sink [4].

The DSTATCOM, in which the dc storage battery also connected with the device to charge in case of over voltage and to discharge in case of under voltage in this way by withdrawing and supplying the reactive power it can compensate the reactive power. Therefore it can improve the power factor and reduce the harmonics in the system.
The DSTATCOM proposed here maintains the voltage magnitude within the limits by eliminating the voltage sags and swells in the system. The DSTATCOM [8] active part in eliminating the voltage sags and swells in the power system under faulty conditions is as follows [10], [11]:

\subsection{Voltage Sag}

If there is sudden increase in the load then the voltage in the line decreases rapidly due to the decrease in the terminal voltage at the receiving end or the utility side. This sudden change in the terminal voltage appears as a sag [7] in the voltage in the line. In this case the proposed DSTATCOM responds by supplying the reactive power to the system so that the voltage magnitude and hence its waveform can be regained [9].

\subsection{Voltage Swell}

If there is a sudden decrease in the load then the voltage in the line increases rapidly due to the increase in the terminal voltage at the receiving end or the utility side. This sudden change in the utility side terminal voltage appears as voltage swell in the line. The DSTATCOM here makes the voltage value to be maintained in limits by absorbing the reactive power in the line.

It is used to improve the power factor and for the voltage regulation in the system. In the system it can absorb the reactive power and improve the voltage stability. Its response time is shorter than SVC [5].

\section{VOLTAGE SOURCE CONVERTER (VSC)}

VSC is a bidirectional component. As per the requirement this device converts the $\mathrm{AC}$ voltage to $\mathrm{DC}$ or $\mathrm{DC}$ voltage to $\mathrm{AC}$ voltage as per the requirement. It consists of diode, op-amp, and transistor circuit. VSC designed for this model works in two cases.

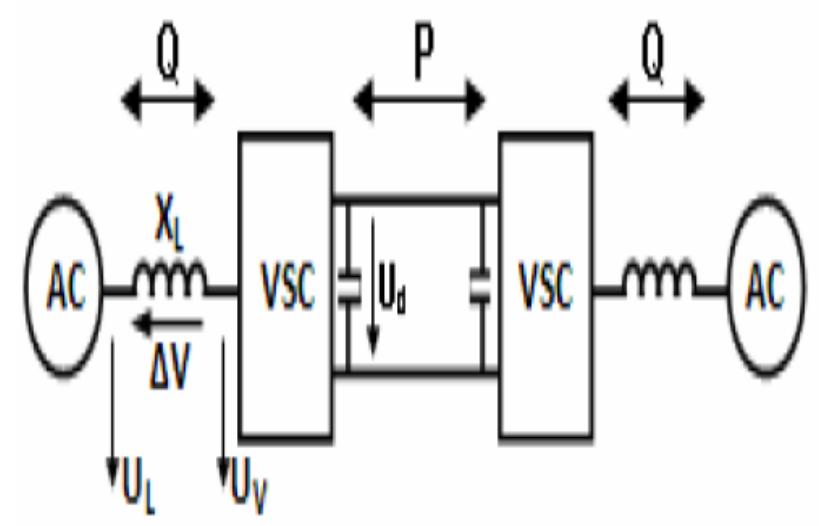

Fig 1: Voltage source converter 


\subsection{Inverter Mode of Operation}

To convert the storage voltage or battery voltage into ac voltage to compensate the reactive power deficiency in line.

\subsection{Converter Mode of Operation}

To convert the excessive power in the line into the corresponding $\mathrm{dc}$ voltage equivalent and then to give to the storage component which acts as a source for the rectifying mode of operation.

The operation mode is automatically activated by activating the switching signals to the switches which are generated by a suitable control technique.

\section{DESIGN OF VSC}

VSC-based unit utilizes several important Technological developments:

- High voltage valves with series-connected MOSFETs

- Compact, dry, high-voltage dc capacitors

- High capacity control system

There are some specifications in the design of a VSC and they are explained below.
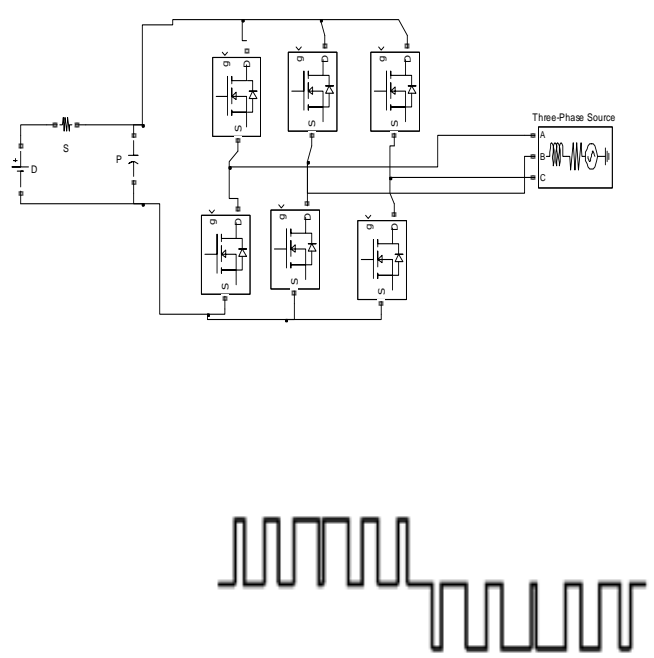

Fig 2: Three-level VSC and its PWM signal

A voltage divider and special gate unit is connected for each MOSFET so that a uniform voltage is associated with each switch. The unit function is to maintain required voltage sharing between valves during the operation conditions of normal situations as well as during disturbance and fault conditions. There may be a case of failure of switches during short circuit conditions. So a short circuit control mode is available to look after that case. The switching of these MOSFET switches is done by using PWM technique. The amplitude and phase angle of the AC voltage can be controlled accordingly. With the control of both amplitude and phase angle the active power and reactive power can be controlled respectively. Both the active power and dc voltage can be controlled individually by the active power control loop. Similarly the ac voltage or the reactive power can be controlled individually by the reactive power control loop.

\section{CONTROL ALGORITHM}

In this paper a new control design proposed to make the DSTATCOM adaptive in the system, it can control the harmonics, power factor, distorted voltage waveforms and it can compensate the reactive power. The main objective of this control scheme is to compensate the distorted waveforms, mitigate the voltage magnitude at that point where the variable load connected.

In this paper a PWM technique based VSC strategy used. The difference of reference voltage to RMS value of the terminal voltage will generate the error signal which is the input signal for the controller. Therefore this signal processed by PI controller and generated signal will transfer to the PWM, which will generate the gating pulse for the MOSFETs.

\section{SIMULINK DIAGRAM}

In this paper a test system designed in which load is producing sag/swell into the system, injecting harmonics in the system and reducing the voltage stability [6]. For the improvement of power quality in distribution system a DSTATCOM connected to the system in parallel. DSTATCOM property is to compensate the reactive power of the system, which is generated by the load by closing and opening of circuit breaker.

Here a test model taken in which source that is generator of $230 \mathrm{kv}, 50 \mathrm{~Hz}$ taken, which is fed to the primary side of a $3-$ winding transformer [5]. Further it distributed into two parallel feeders, at each terminal load connected having different resistance value. A DSTATCOM is connected to the system and it connected to the tertiary winding of transformer also to support instantaneously. DSTATCOM connected by using circuit breaker for controlled operation for particular time.

Here considering two cases, in Case I by opening circuit breaker 2 the load injecting voltage sag in the system in case of without DSTATCOM by opening circuit breaker 1, which can measured by scopes and further to mitigate the voltage sag there is DSTATCOM connected in the system in parallel by closing circuit breaker 1, which is shown in Figure 3. Figure 4 showing the FFT analysis when voltage sag produced without DSTATCOM and Figure 5 showing the THD (Total Harmonic Distortion). Therefore after connecting the DSTATCOM in the system by closing the circuit breaker 1, it will supply the reactive power and by compensating the reactive power it will mitigate the voltage sag. The FFT analysis of voltage sag 
mitigation is shown in Figure 6 and Figure 7 representing THD reduction after introducing the DSTATCOM in the system.

In Case II, by closing the circuit breaker 2 the load is introducing the voltage swells in the system, then there is a need to compensate it, to mitigate the swells of the system DSTATCOM connected in parallel as shown in Figure 8. Therefore the voltage swells produced by load is shown in Figure 9 and THD generation is shown in Figure 10. By closing the circuit breaker 1 the DSTATCOM introduced in the system which will absorb the reactive power and it will mitigate the voltage swell. Figure 11 showing the result of voltage swell mitigation after connecting the DSTATCOM and Figure 12 showing the THD reduction in voltage swells.

Table I content the THD comparison of voltage sag and swell with and without DSTATCOM. In case of voltage sag THD reduced by $61.05 \%$ and in case of voltage swell THD reduced by $60.24 \%$.

\subsection{Case I Using DSTATCOM for the Sag}

\section{Mitigation:}

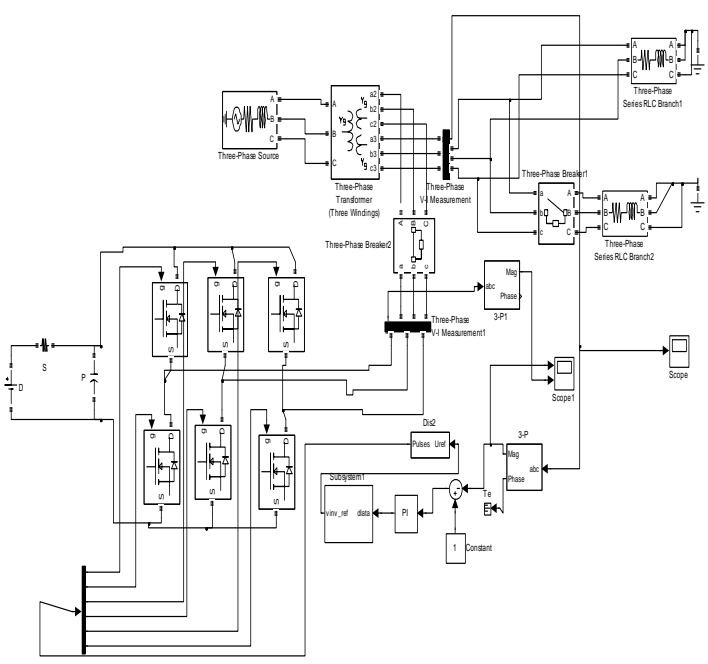

Fig 3: Sag Mitigation

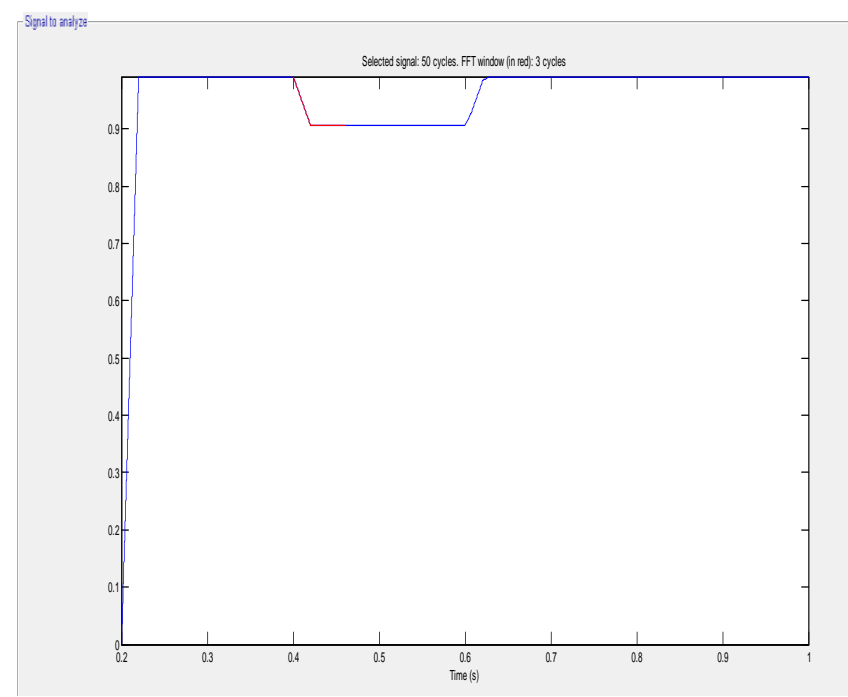

Fig 4: Sag generation in the system

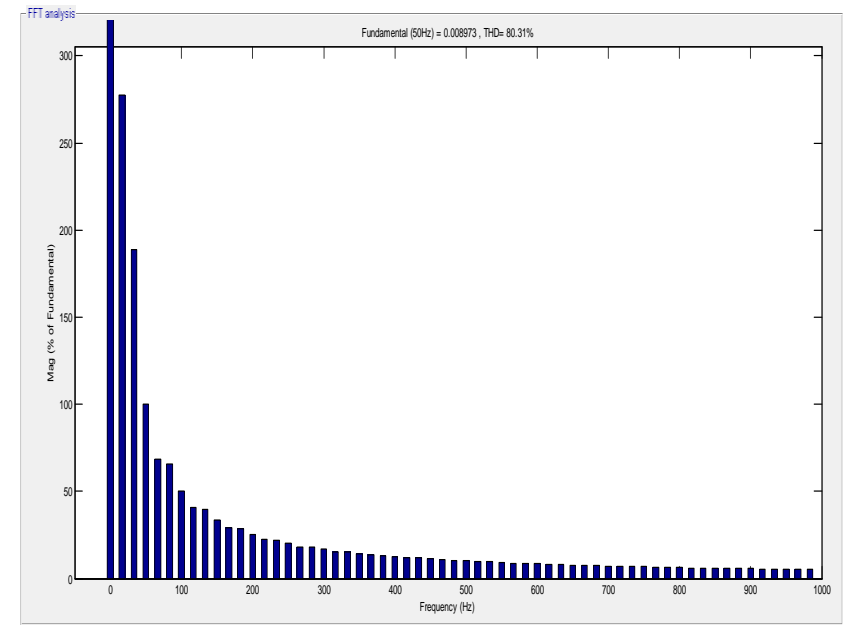

Fig 5: FFT analysis of THD during sag

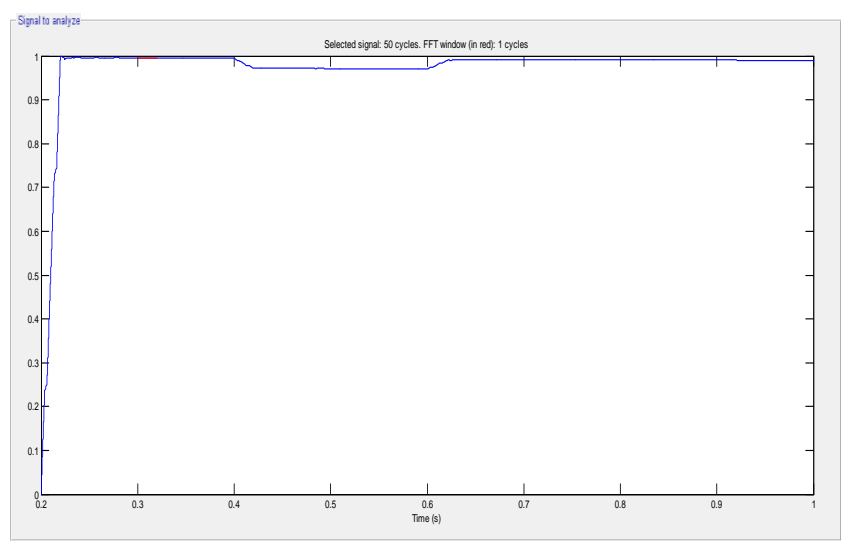

Fig 6: Sag Mitigation 


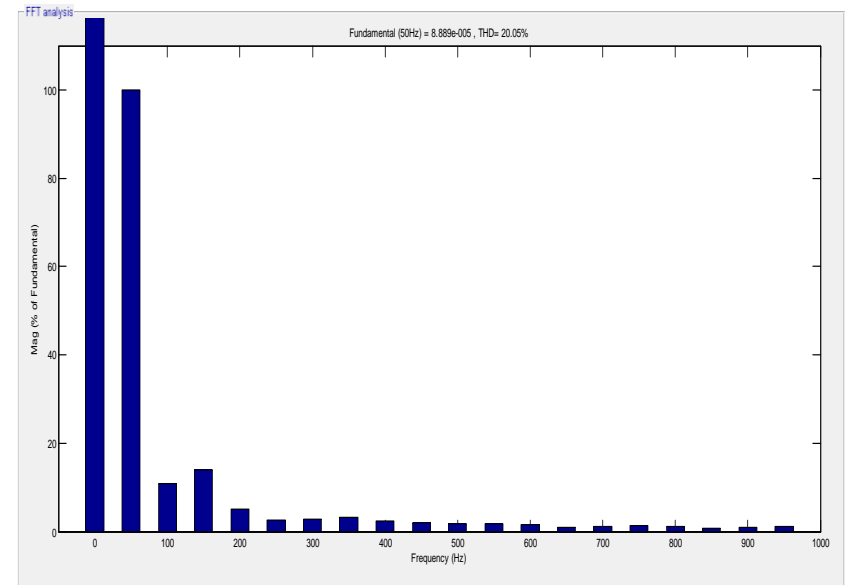

Fig 7: FFT analysis of THD during sag mitigation

\subsection{Case II Using DSTATCOM for the Swell}

\section{Mitigation}

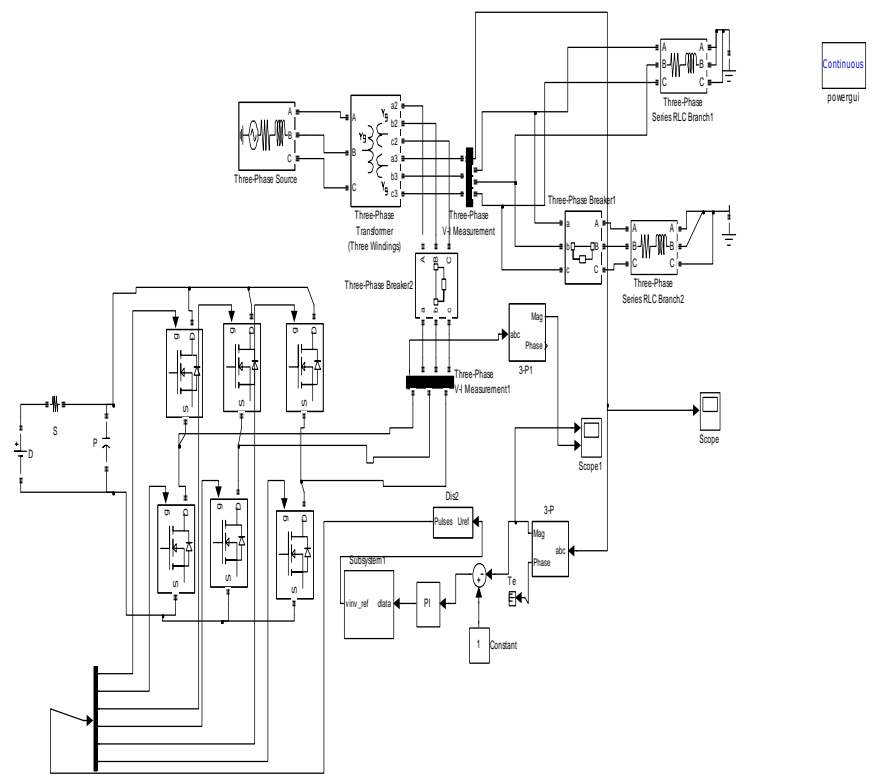

Fig 8: Swell Mitigation

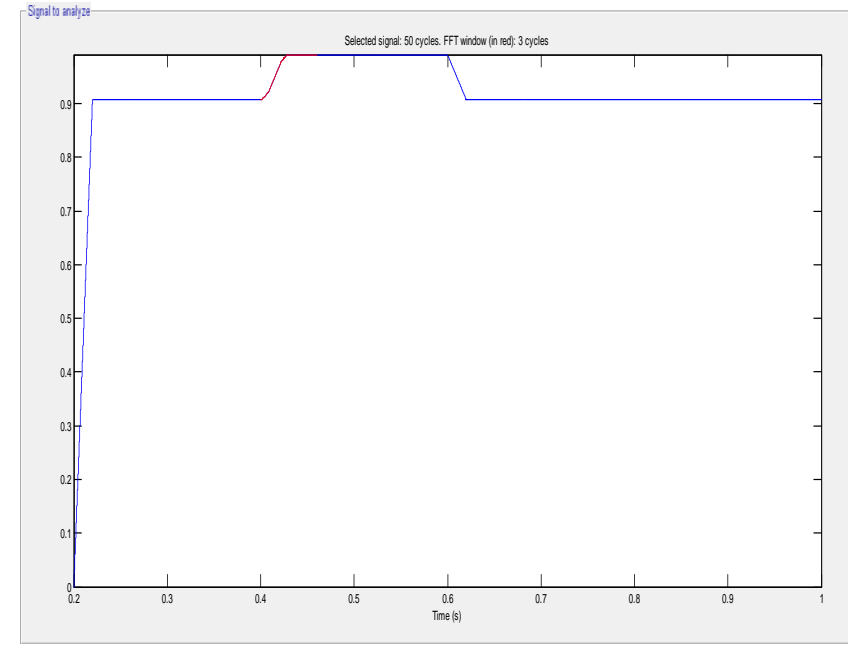

Fig 9: Swell generation in the system

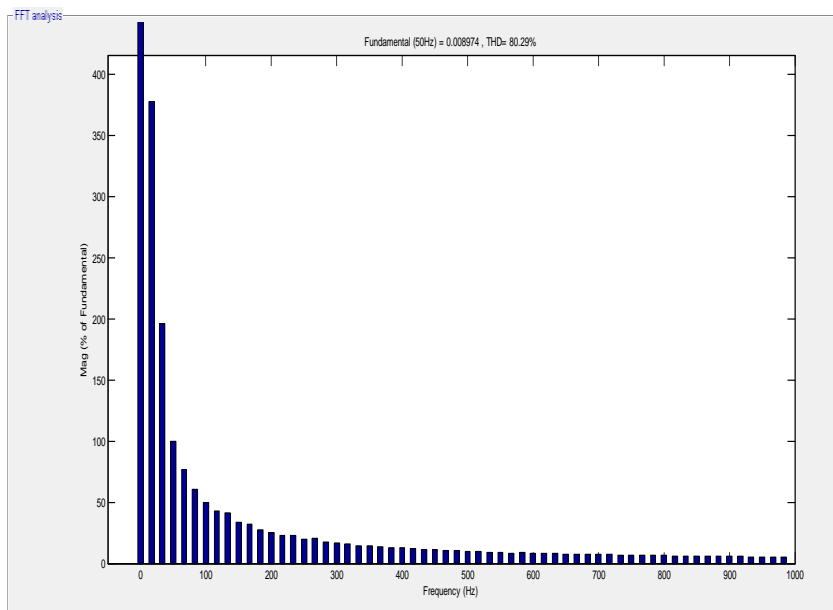

Fig 10: FFT analysis of THD during swell

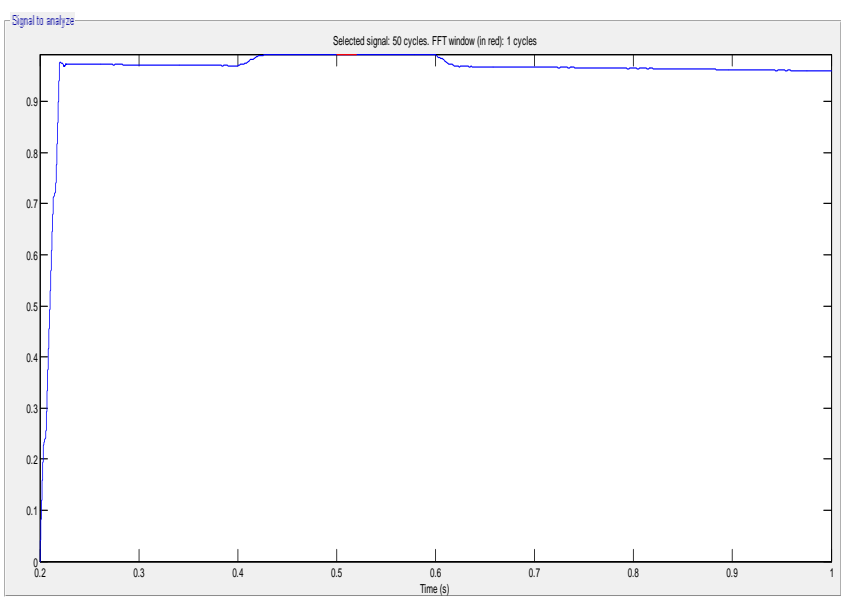

Fig 11: Swell Mitigation 


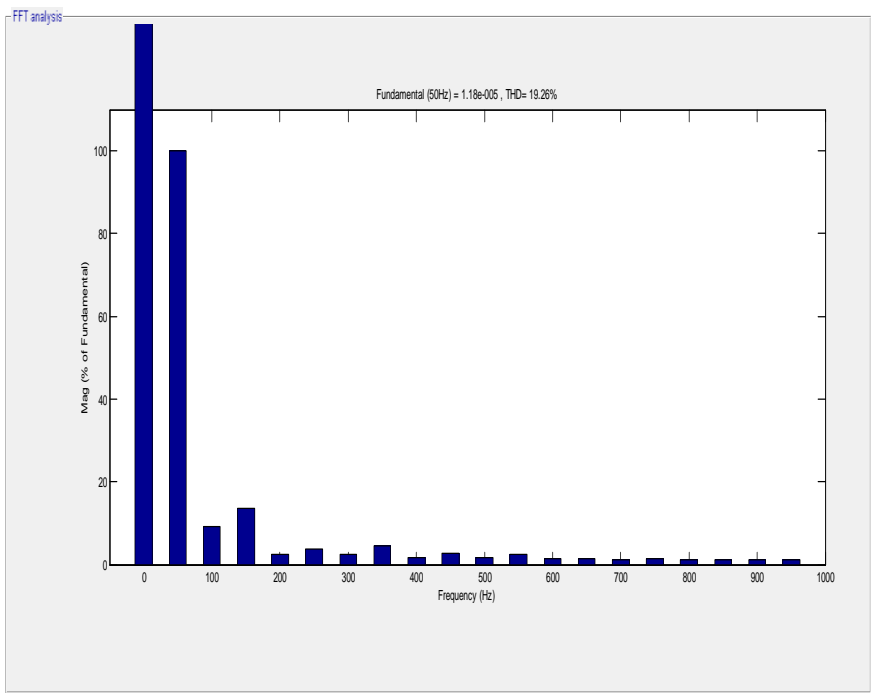

Fig 12: FFT analysis of THD during swell mitigation

Table -1: Total Harmonic Distortion

\begin{tabular}{|c|c|c|}
\hline THD in \% & $\begin{array}{c}\text { Without } \\
\text { DSTATCOM }\end{array}$ & $\begin{array}{c}\text { With } \\
\text { DSTATCOM }\end{array}$ \\
\hline For Sag & $80.31 \%$ & $19.26 \%$ \\
\hline For Swell & $80.29 \%$ & $20.05 \%$ \\
\hline
\end{tabular}

\section{CONCLUSIONS}

In this test system the voltage sag and swell is produced by resistive load and it is mitigated by introducing the DSTATCOM into the system.THD reduced by $61.05 \%$ in the case of voltage sag and THD reduced by $60.24 \%$ in the case voltage swells. Therefore power quality improved by controlling the voltage magnitude at constant level. Therefore it can be implementing in the transmission line to maintain the voltage at constant magnitude.

\section{REFERENCES}

[1]. Lamarre. L, "Problems with Power Quality," Epri Journal, 16(5), pp. 14-23,July/Aug. 1991.

[2]. IEEE Std. 519-1992, "IEEE Recommended Practices and Requirements for Harmonic Control in Electric Power Systems.

[3]. Wyk. J.D. Van, "Power Quality, Power Electronics and Control,” EPE Brighton, Vol. 1, pp. 17-38, 1993.

[4]. Bhim Singh, Sabha Raj Arya*" Design and control of a DSTATCOM for power quality improvement using cross correlation function approach", International Journal of Engineering, Science and Technology Vol. 4, No. 1, 2012, pp. 74-86.
[5]. Sai Kiran Kumar.Sivakoti, Y.Naveen Kumar, D.Archana, "Power Quality Improvement In Distribution System Using DSTATCOM In Transmission Lines", International Journal of Engineering Research and Applications (IJERA), Vol. 1, Issue 3, pp.748-752

[6]. Mithilesh Kumar Kanaujia and Dr. S.K. Srivastava, "Power Quality Enhancement with D-Statcom Under Different Fault Conditions", International Journal of Engineering Research and Applications, Vol. 3, Issue 2, pp. 828-833, March -April 2013.

[7]. Bollen, M.H.J.," Voltage sags in three-phase systems" Power Engineering Review, IEEE, Vol. 21, Issue: 9, Sept. 2001, pp: 8 - 11, 15.

[8]. R.Mienski,R.Pawelek and I.Wasiak., "Shunt Compensation for Power Quality Improvement Using a STATCOM controller: Modelling and Simulation",

IEEE Proce., Vol.151, No.2, March 2004.

[9]. G. Yaleinkaya, M.H.J. Bollen, P.A. Crossley, "Characterization of voltage sags in industrial distribution systems", IEEE transactions on industry applications, vol.34, no. 4, July/August, pp. 682-688,

1999.

[10]. Haque, M.H., "Compensation of distribution system voltage sag by DVR and D-STATCOM", Power Tech Proceedings, 2001 IEEE Porto, vol.1, pp.10-13, Sept. 2001.

[11]. Anaya-Lara O, Acha E., "Modeling and analysis of custom power systems by PSCAD/EMTDC", IEEE Transactions on Power Delivery, Vol.17, Issue:1, Jan. 2002, Pages:266 - 272.

\section{BIOGRAPHIES}

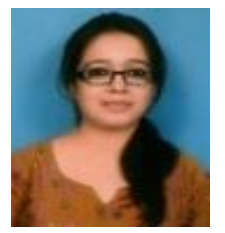

Priyanka rani passed B.tech(Electrical) from Jaipur National University in 2012 and pursuing M.tech in Lovely Professional University in session 2012-2014, Phagwara.My current research work on the "Comparison of performance of DSTATCOM With Active Filter for Power Quality Enhancement".

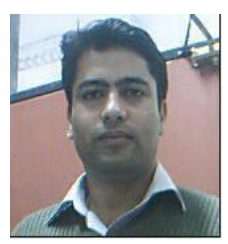

Er.Ashish Sharma passed B.Tech in 2001 and M.Tech in 2006 from Punjab Technical University Jalandhar. Presently he is working as Astt. Prof. in Lovely Professional University, Phagwara. His current research interests include power system optimization, electric machine analysis and self excited induction generators. 